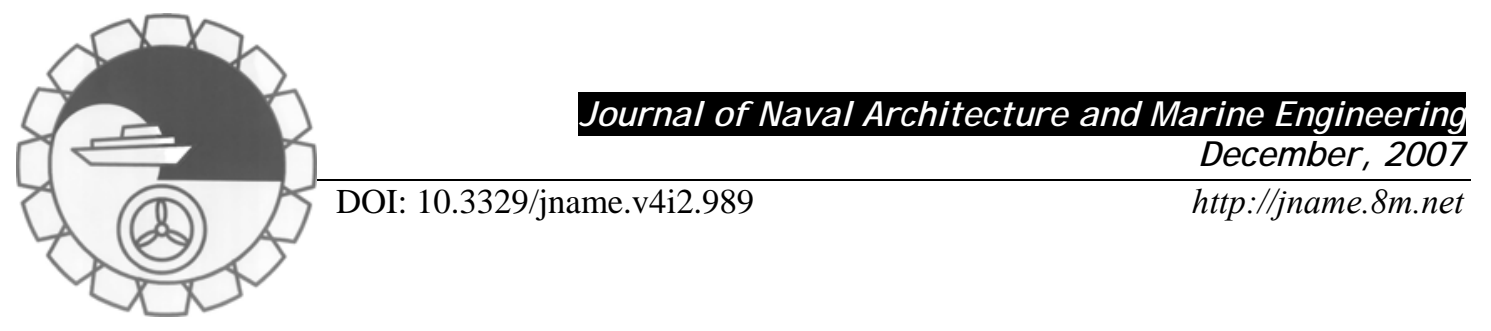

\title{
EXPERIMENTAL RESEARCH ON MARINE PODDED PROPULSORS
}

\author{
Mohammed F Islam ${ }^{1}$, Brian Veitch ${ }^{2}$ and Pengfei Liu ${ }^{3}$
}

${ }^{1}$ Doctoral Candidate, Faculty of Engineering and Applied Science, Memorial University of Newfoundland, St. John's, NL A1B 3X5, Canada, Tel.: +1-709-743-5627, E-mail: islam@engr.mun.ca , ${ }^{2}$ Professor, Faculty of Engineering and Applied Science, Memorial University of Newfoundland, St. John's, NL A1B 3X5, Canada, ${ }^{3}$ Senior Research Officer, Institute for Ocean Technology (IOT), National Research Council, St. John's, NL A1B 3T5, Canada.

\section{Abstract}

This paper describes a research program on podded propulsors that combines parallel developments in numerical prediction methods and experimental evaluation. Amongst the hydrodynamic issues that have been identified and addressed are questions regarding the effects of hub taper angle, pod-strut configurations, static azimuthing conditions, pod-strut interactions, gap pressure, pod gap and pod-strut geometry on podded propulsors' performance. On the experimental side, a pod dynamometer system consisting of a sixcomponent global dynamometer and a three-component pod dynamometer were designed, manufactured and used to perform measurements on propeller thrust and torque and unit forces and moments in the three orthogonal directions in pusher and puller configurations in open water conditions. Four propellers with the same blade sections but different hub taper angles were designed and used to fit with eighteen pod-strut shells. Among the shells, two podstrut models were based on the average dimensions of commercial pods and used to study the hub angle, pod configuration, pod gap, gap pressure and azimuthing conditions effect on propulsive performance. The other sixteen pods were designed and manufactured to study the effect of five geometric parameters on hydrodynamic performance using a design of experiments technique. In another study, an experimental method was implemented in a cavitation tunnel to evaluate the wake/strut interaction of a podded propeller model. All of the measurements showed consistency.

Keywords: Podded propulsors, pusher and puller propellers, propulsive performance, hub taper angle, pod gap distance, azimuthing conditions, wake impingement effect.

\section{NOMENCLATURE}

$T \quad$ Temperature $\left({ }^{\circ}\right)$

$D \quad$ Propeller diameter (m)

$R \quad$ Propeller radius (m)

$N \quad$ Propeller rotational speed (rps)

$V_{A} \quad$ Propeller advance speed, in the direction of carriage motion $(\mathrm{m} / \mathrm{s})$

$Q \quad$ Propeller torque $(\mathrm{Nm})$

$T_{\text {Prop }} \quad$ Propeller thrust (N)

$T_{\text {Unit }} \quad$ Unit thrust (N)

$F_{\mathrm{Y}} \quad$ Unit side force (N)

$F_{\mathrm{Z}} \quad$ Unit vertical force $(\mathrm{N})$

$M_{\mathrm{X}} \quad$ Unit axial moment (Nm)

$M_{\mathrm{Y}} \quad$ Unit transverse moment $(\mathrm{Nm})$

$M_{\mathrm{Z}} \quad$ Unit steering moment (Nm)

$\rho \quad$ Water density $\left(\mathrm{Kg} / \mathrm{m}^{3}\right)$

$g \quad$ Gravitational acceleration $\left(\mathrm{m} / \mathrm{s}^{2}\right)$

$h \quad$ Shaft depth from water level (m)

$P_{a m b} \quad$ Atmospheric pressure $\left(\mathrm{N} / \mathrm{m}^{2}\right)$

$P_{V} \quad$ Vapour pressure $\left(\mathrm{N} / \mathrm{m}^{2}\right)$

$\begin{array}{ll}K_{T \text { Prop }} & \text { Propeller thrust coeff., } T_{\text {Prop }} / \rho n^{2} D^{4} \\ 10 K_{Q} & \text { Propeller torque coeff., } 10 Q / \rho n^{2} D^{5} \\ K_{T \text { Unit }} & \text { Unit thrust coeff., } T_{\text {Unit }} / \rho n^{2} D^{4} \\ K_{F \mathrm{Y}} & \text { Unit side force coeff., } F_{\mathrm{Y}} / \rho n^{2} D^{4} \\ K_{F \mathrm{Z}} & \text { Unit vertical force coeff., } F_{\mathrm{Z}} / \rho n^{2} D^{4} \\ K_{M \mathrm{X}} & \text { Unit axial moment coeff., } M_{\mathrm{X}} / \rho n^{2} D^{5} \\ K_{M \mathrm{Y}} & \text { Unit axial moment coeff., } M_{\mathrm{Y}} / \rho n^{2} D^{5} \\ K_{M \mathrm{Z}} & \text { Unit axial moment coeff., } M_{\mathrm{Z}} / \rho n^{2} D^{5} \\ J & \text { Propeller advance coeff., } V_{A} / n D \\ \eta_{\text {Prop }} & \text { Propeller efficiency, } J / 2 \pi \times\left(K_{\mathrm{Pr} o p} / K_{Q}\right) \\ \eta_{\text {Unit }} & \text { Unit efficiency, } J / 2 \pi \times\left(K_{T \mathrm{Unit}} / K_{Q}\right) \\ \sigma & \text { Cavitation number, } \frac{P_{a m b}+\rho g h-P_{V}}{\frac{1}{2} \rho n^{2} D^{2}} \\ & \quad\end{array}$

$10 K_{Q} \quad$ Propeller torque coeff., $10 Q / \rho n^{2} D^{5}$

$K_{\text {TUnit }} \quad$ Unit thrust coeff., $T_{\text {Unit }} / \rho n^{2} D^{4}$

$K_{F \mathrm{Y}} \quad$ Unit side force coeff., $F_{\mathrm{Y}} / \rho n^{2} D^{4}$

$K_{F Z} \quad$ Unit vertical force coeff., $F_{\mathrm{Z}} / \rho n^{2} D^{4}$

$K_{M \mathrm{X}} \quad$ Unit axial moment coeff., $M_{\mathrm{X}} / \rho n^{2} D^{5}$

$K_{M Y} \quad$ Unit axial moment coeff., $M_{\mathrm{Y}} / \rho n^{2} D^{5}$

$K_{M Z} \quad$ Unit axial moment coeff., $M_{\mathrm{Z}} / \rho n^{2} D^{5}$

$J \quad$ Propeller advance coeff., $V_{A} / n D$

$\eta_{\text {Prop }} \quad$ Propeller efficiency, $J / 2 \pi \times\left(K_{\operatorname{Pr} o p} / K_{Q}\right)$

$\eta_{\text {Unit }} \quad$ Unit efficiency, $J / 2 \pi \times\left(K_{\text {TUnit }} / K_{Q}\right)$ $\frac{1}{2} \rho n^{2} D^{2}$ 


\section{Introduction}

A podded propulsion system consists of a fixed pitch propeller driven by an electric motor through a short shaft. The shaft and motor are located inside a pod shell. The pod unit is connected to the ship's hull through a strut and slewing bearing assembly. This assembly allows the entire pod unit to rotate and thus the thrust developed by the propeller can be directed anywhere in the horizon in a $360^{\circ}$ compass. The podded propeller arrangement eliminates the requirement for a rudder and additional appendages such as shaft brackets. This arrangement results in lower appendage drag. The shorter shaft can also help reduce noise and vibration. The propeller works in more uniform flow, which reduces load variations and risk of cavitation. Podded propulsion systems also yield much better maneuverability than conventional screw propellers, especially in confined water operation. Despite these advantages, podded propulsion systems have some disadvantages, such as high capital cost and high loads while operating in oblique flow conditions. Fig. 1 shows a comparison of arrangements of a conventional propeller-rudder propulsion system and a puller podded propulsion system.

Basically, two types of pod propulsion systems are used in the marine industry, namely, pusher pod propulsion system and puller pod propulsion system. In a pusher pod propulsion system, the propeller is attached to the after end of the pod, thus the propeller pushes the unit. In a puller (also termed as tractor) pod propulsion system the propeller is attached to the fore end of the pod, thus the propeller pulls the unit.
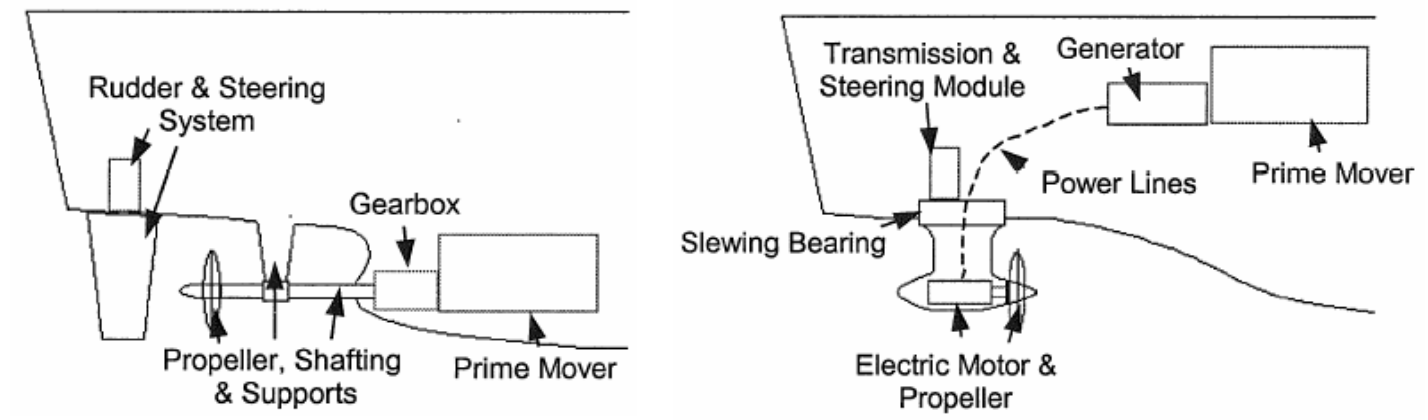

Figure 1: Conventional propulsion system (left) vs. podded propulsion system (right).

Our research program entitled "Systematic Investigation of Azimuthing Podded Propeller Performance" combines parallel developments in numerical prediction methods and experimental evaluation. The work addresses gaps in the knowledge concerning podded propeller performance, performance prediction, and performance evaluation. Some of the short term objectives of the project are outlined as follows:

\section{- Short-term objectives:}

$\checkmark$ Quantify systematically the effects of podded propulsor configuration variations on propulsion performance.

$\checkmark$ Develop computational methods for podded propeller performance prediction.

$\checkmark$ Develop new instrumentation for performance evaluation of podded propellers at model scale.

Amongst the hydrodynamic issues that have been identified and addressed are questions regarding the effects of hub taper angle (Islam 2004, Islam et al. 2004, Islam et al. 2005, Islam et al. 2006, Islam et al. 2007, Taylor et al. 2005, Taylor 2005), pod-strut configuration (Islam 2004 and Taylor 2005), podstrut interactions (He et al. 2005a and He et al. 2005b), gap pressure (MacNeill 2004), pod-strut geometry (Molloy et al. 2005, Islam et al. 2006 and Islam et al. 2007), pod gap effect (Islam et al. 2007a) and static azimuthing conditions (Islam et al. 2007b) on podded propulsor performance. This paper presents a technical overview of the experimental investigations being done to study various hydrodynamic aspects of podded propulsors in open water conditions. 


\section{Experimental Apparatus and Approach}

A custom-designed dynamometer system (MacNeill et al. 2004) was designed and used for the measurements. A wave shroud was attached to the frame of the test equipment and placed just above the water surface. The bottom of the shroud stayed 3 to $5 \mathrm{~mm}$ above the water surface to suppress waves caused by the strut piercing the surface. A motor fitted above the shroud drove the propeller via a belt system. The center of the propeller shaft was $1.5 D_{\text {Prop }}$ below the water surface. The part of the shaft above the strut (the shaft connected the pod unit to the main drive of the equipment) went through the shroud. Figs. 2 and 3 show the different parts of the experimental apparatus.

A dynamometer with the ability to measure propeller and pod forces and moments was used to measure the following items:

$\checkmark$ Propeller thrust $\left(T_{\text {Prop }}\right)$ and torque $(Q)$

$\checkmark \quad$ Unit longitudinal force $\left(F_{\mathrm{X}}\right)$ and moment $\left(M_{\mathrm{X}}\right)$

$\checkmark$ Unit transverse force $\left(F_{\mathrm{Y}}\right)$ and moment $\left(M_{\mathrm{Y}}\right)$

$\checkmark$ Unit vertical force $\left(F_{\mathrm{Z}}\right)$ and moment $\left(M_{\mathrm{Z}}\right)$

Also, the water temperature, carriage speed, $V_{A}$ and the rotational speed of the propeller, $n$, were measured. The dynamometer system has two major parts. The first part is the pod dynamometer, which measures the torque of the propeller at the propeller shaft. The propeller thrust is measured in two different locations. The first location for the thrust measurement is inside the hub of the propeller and the second location is on the propeller shaft at the end the pod opposite to the propeller. The second part of the system is the global dynamometer, which measures the unit thrust at the location above the wave shroud. The carriage speed and rotational speed of the propeller are recorded in the standard manner.

Fig. 2 shows an assembly drawing of the experimental apparatus, which has the following major components.

1. Lift System Drive Train: Consists of the electric drive motor, timing pulleys and drive belts to operate lead screws. Each lead screw has a timing pulley to allow for synchronous operation of all four screws to raise or lower the pod unit.

2. Lift System Framework: Supporting structure for the lift system.

3. Fixed Frame: Frame that rests on the towing carriage rails and provides stability for the rest of the instrumentation package.

4. Live Frame: This frame houses the global dyno instrumentation package. It is mounted on four lead screws that allows the entire pod unit to be raised out of the water. This frame moves with the pod unit during lifting and it is secured to the fixed frame during testing.

5. Main Drive Train: Consists of a 3-hp electric motor coupled to a $90^{\circ}$ gearbox. This gearbox is connected to the main pulley, which drives the belt that rotated the propeller shaft.

6. Instrumented Pod Unit: Houses the propeller and pod geometry and contains the sensors for thrust, torque, drag and gap pressure. Fig. 3 shows the dynamometer and the lifting system installed on the towing tank rails.

The pod dynamometer consists of the most complex aspect of the design, where most of the measurements are made, including the following:

$\checkmark$ Propeller torque - is measured with strain gauges installed on the propeller shaft, just behind the propeller hub and ahead of the shaft seals.

$\checkmark$ Propeller thrust (at the propeller end) - is measured with a load cell mounted in the propeller hub. The hub is designed to accommodate propeller changes during testing without disturbing the instrumentation. Measured thrust is the total blade thrust, including effects of the hub. Effects of the gap between the hub and pod shell are isolated.

$\checkmark$ Propeller thrust at the shaft end, internal to pod - is measured with a load cell mounted in the pod, centrally located at the shaft end. This thrust is subjected to the effects of the gap between the prop hub and pod shell, as well as any other losses in the pod.

$\checkmark \quad$ Shell drag - is measured with a load cell mounted between the pod shell and the pod instrumentation. The shell is free to float on linear bearings in the axial direction. Shell drag force is measured parallel to the shaft axis. 
$\checkmark$ Propeller gap pressure - is measured with five pressure transducers mounted in the pod shell end, on the face opposite the rotating propeller hub. Each sensor is mounted at a different radius value to measure any variation of pressure with radius. All sensors are located in a plane parallel with the free surface to negate the effects of pressure due to different depths.

For the study the thrust load-cell and the torque gauge were calibrated using ITTC recommended procedure (2002b). The global dynamometer was calibrated using the method described by Hess et al. (2000) and Galway (1980). The methods take into account cross talk between the six load cells and produce an interaction matrix to convert the voltage output into the forces and moments in the three coordinate directions. The definition of the forces, moments and co-ordinates that were used to analyze the data and present the results is shown in Fig. 4. The coordinate centre (pod centre) coincided with the intersection of the horizontal axis through the propeller shaft centre and the vertical axis through the strut shaft center.

Four propellers with the same blade section but different hub taper angles (Liu 2006) were designed and used to fit with eighteen pod-strut shells in pusher and puller configurations. Among the pods, two pod-strut models were based on the average dimensions of commercial pods and used to study the hub angle effect on propulsive performance. The other sixteen pods were designed and manufactured to study the effect of geometric parameters on hydrodynamic performance using a design of experiments technique (Montgomery 2005). The two average pods were also used to study the hydrodynamic performance variations with the change of advance coefficients and static azimuthing conditions (Islam et al. 2007b). The second average pod was used to study the pod gap effect in straight course and azimuthing conditions (Islam et al. 2007b). In another study, an experimental method was implemented in a cavitation tunnel to evaluate the wake/strut interaction of a podded propeller model (He et al. 2005a and He et al. 2005b). The first average pod was used for this study.

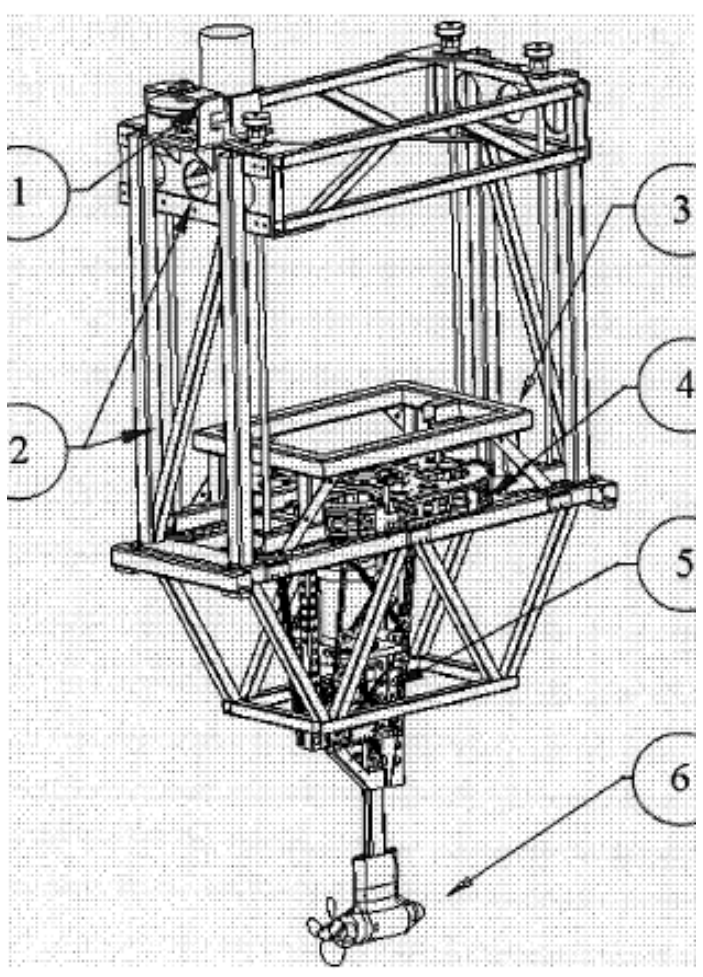

Figure 2: Different parts of the experimental apparatus used in the podded propulsor tests (MacNeill et al. 2004).

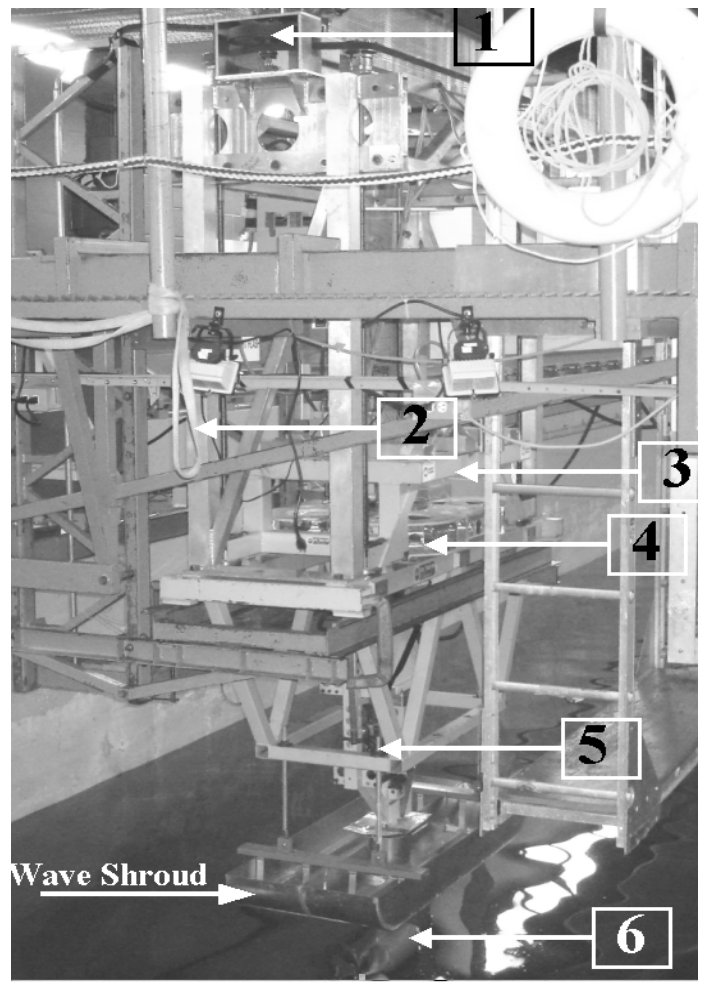

Figure 3: Pod dynamometer system installed on the OERC towing tank rails. 


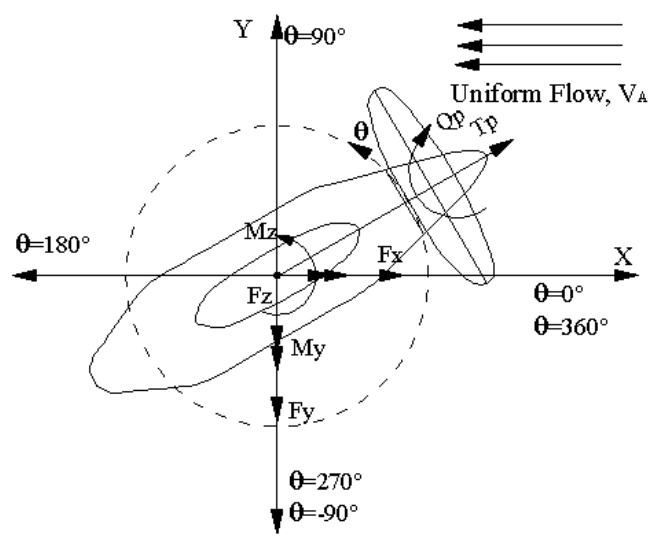

Azimuthing Puller Podded Propulsor Left handed propeller

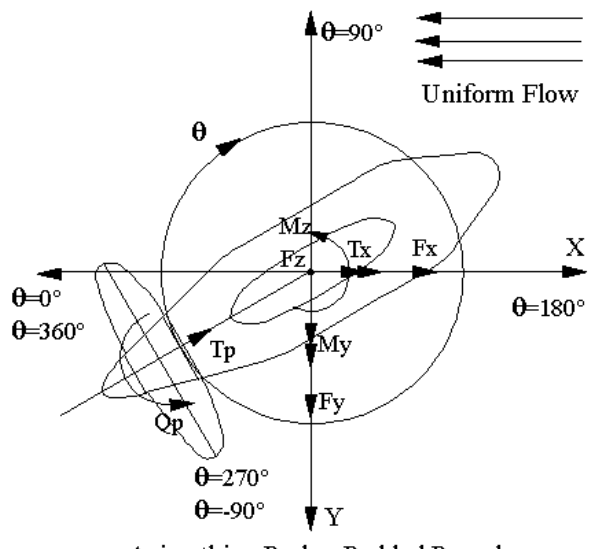

Azimuthing Pusher Podded Propulsor Right handed propeller

Figure 4: Definitions of forces, moments, coordinate of the puller and pusher azimuthing podded propulsors.

\section{Measurements and Results}

The experimental study of podded propulsors was categorized into two major groups: propeller only case (baseline propellers) and pod unit case (propeller with pod body). The study of "propeller only case” essentially consisted of the study of hub taper angle (Islam, 2004) of podded propellers in open water and cavitating conditions. The study of "pod unit" consisted of the study of hub angle, pod configuration, pod geometry, pod gap, static azimuthing conditions and wake/strut interactions of the pod unit in pusher and puller configurations. A brief overview of the studies is outlined in the following sections.

\subsection{Propeller only cases}

In this part of the research work, the effect of hub angle on the performance of the podded propellers in open water and cavitating conditions was studied (Islam 2004, Islam et al. 2004, Islam et al. 2005, Islam et al. 2006, Islam et al. 2007, Taylor et al. 2005 and Taylor 2005). The definitions of hub angle and propeller configurations are shown in Fig. 5. Fig. 6 shows the four model propellers used in the study for the propeller only case.

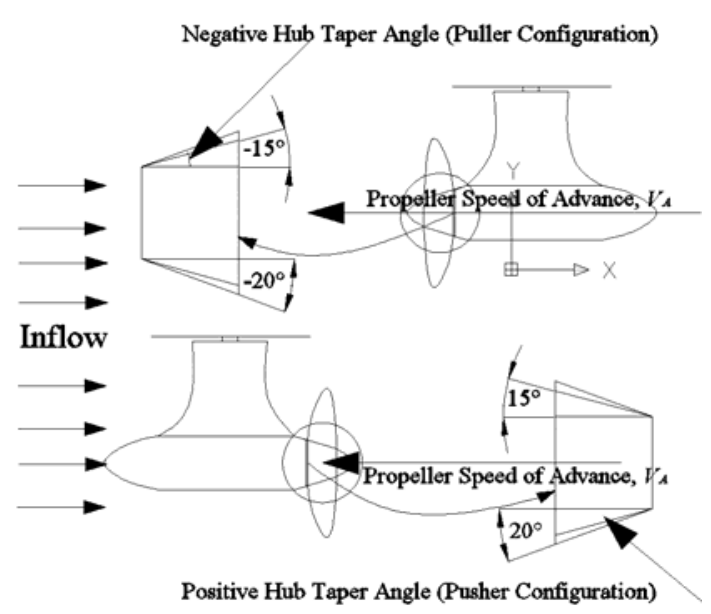

Figure 5: Podded propulsion system: puller and pusher types and the definition of hub taper angle.

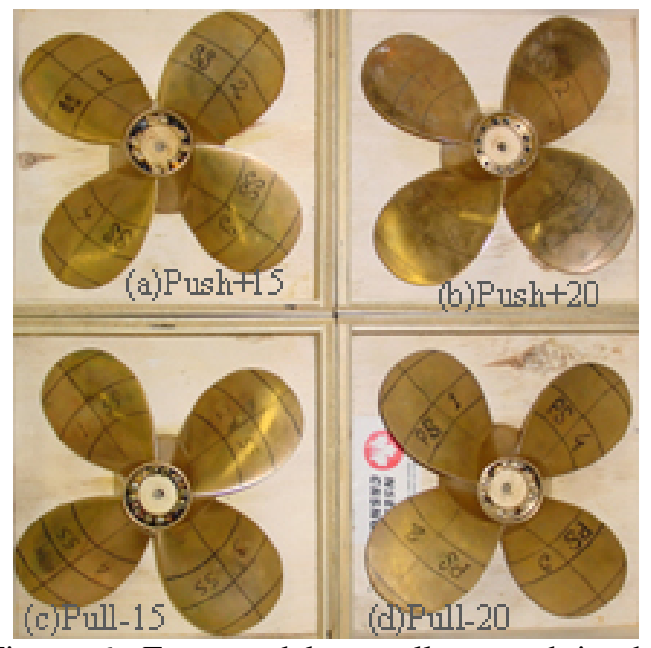

Figure 6: Four model propellers used in the study for the "Propeller Only Case". 


\subsubsection{Hub angle effect in opens conditions}

Taylor (2005) studied the effect of hub taper angle on the performance of a podded propeller (propeller without pod-strut body) in open water conditions. Fig. 7 shows some of the results obtained from the investigation. The conclusions derived from the study are:

- For open water conditions, the actual propellers used in pull configuration podded propellers perform slightly better than an identical propeller designed for use on push configuration podded propellers. Pull propellers have higher bollard thrust and torque coefficients than the push ones as well as higher maximum efficiency.

- In general, increasing the hub taper angle tends to increase the propeller thrust and torque at the bollard condition - although the degree of this influence depends on the specific configuration. Furthermore, increasing the hub taper angle tends to cause an overall lower propeller efficiency and lower unit efficiency at higher advance coefficients - again with the degree of influence depending on the specific configuration.

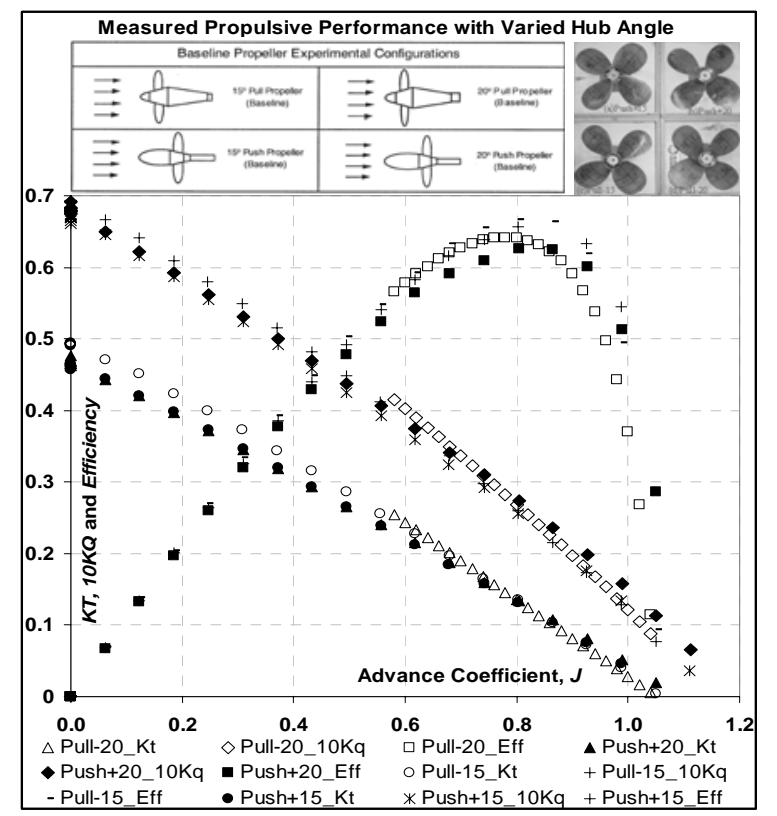

Figure 7: Performance characteristics of podded propeller (propeller only case) with four different hub taper angles.

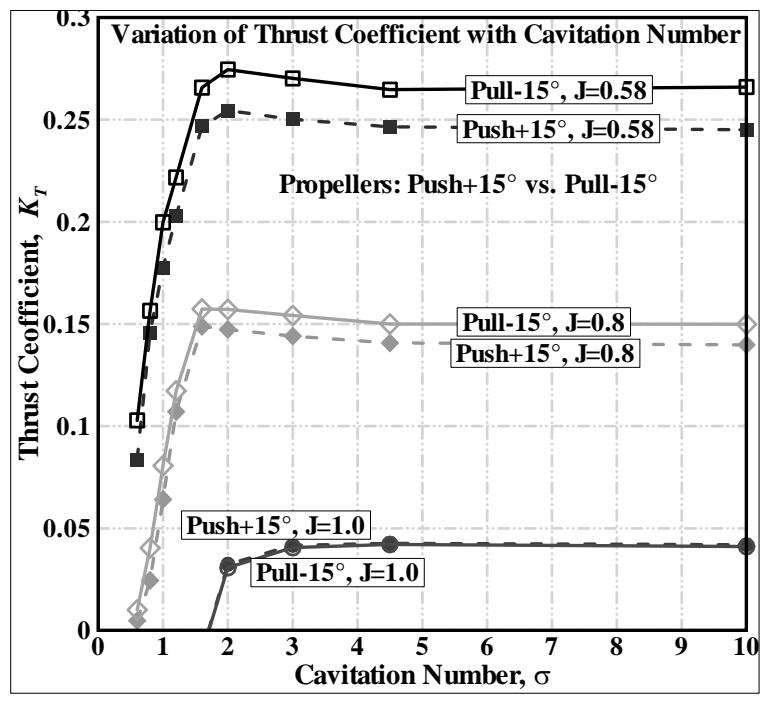

Figure 8: Comparison of thrust coefficient (Push $+15^{\circ}$ and Pull-15 ${ }^{\circ}$ propellers) variation with cavitation number for fixed advance coefficients.

\subsubsection{Hub angle effect in cavitating conditions}

Islam et al. $(2005,2007)$ studied the effect of hub taper angle on the performance of podded propeller in various cavitating conditions. Fig. 8 shows a comparison of propeller thrust coefficient of two propellers with opposite hub taper angles. Fig. 9 shows the two propellers operating under cavitation at specified conditions. The conclusions derived from the study are:

- All of the four propellers showed similar cavitation and inception patterns at the same operating conditions.

- For both pusher and puller propellers, increasing hub taper angle decreased the efficiency at all cavitating conditions. The decreasing effect in efficiency with higher taper angle was observed at all cavitation numbers and was more obvious at higher advance coefficients.

- At all cavitation numbers, the puller propellers produced more thrust and torque than the pusher propellers at lower advance coefficients and the difference decreased with increasing advance 
coefficient (up to 0.7 ). At an advance coefficient of 0.8 , the pusher propeller with $20^{\circ}$ hub angle produced more thrust than the puller propeller with $20^{\circ}$ hub angle.

- The differences in thrust coefficient and efficiency between the pusher propellers and the puller propellers remained the same at all cavitation numbers for the entire range of advance coefficients. The differences were almost equal to the differences that existed in open water condition. The relative performance of the pushing and the pulling propellers were almost the same under the various cavitating conditions.

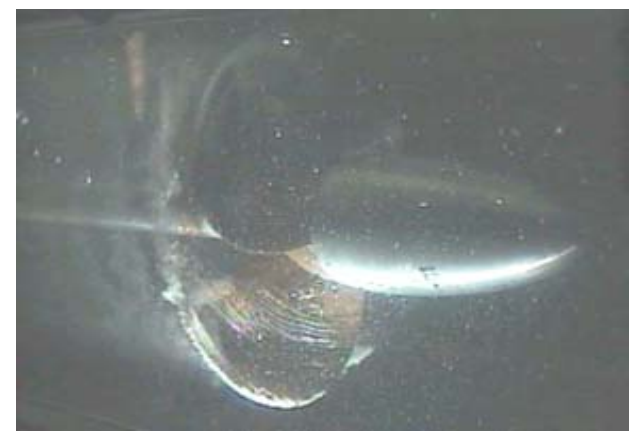

Push+15; $\sigma=1.0 ; J=0.50$;

$K_{T}=0.201 ; 10 K_{Q}=0.348$

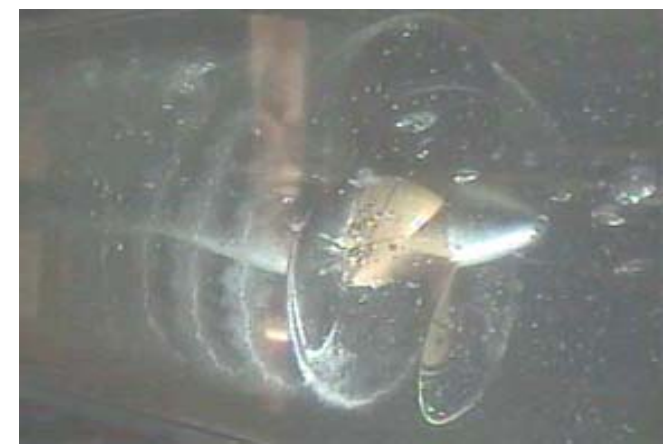

Pull-15; $\sigma=1.0 ; J=0.47$;

$K_{T}=0.232 ; 10 K_{Q}=0.376$

Figure 9: Observation of cavitation characteristics of two propellers (Push $+15^{\circ}$ and Pull- $15^{\circ}$ propellers) at the specified operating conditions.

\subsection{Propeller with pod body (unit) cases}

The study of the pod unit (propeller attached to pod-strut body) was carried out in two groups: study in straight-ahead conditions and study in azimuthing conditions. The pod units were tested in both pusher and puller configurations and in open water conditions.

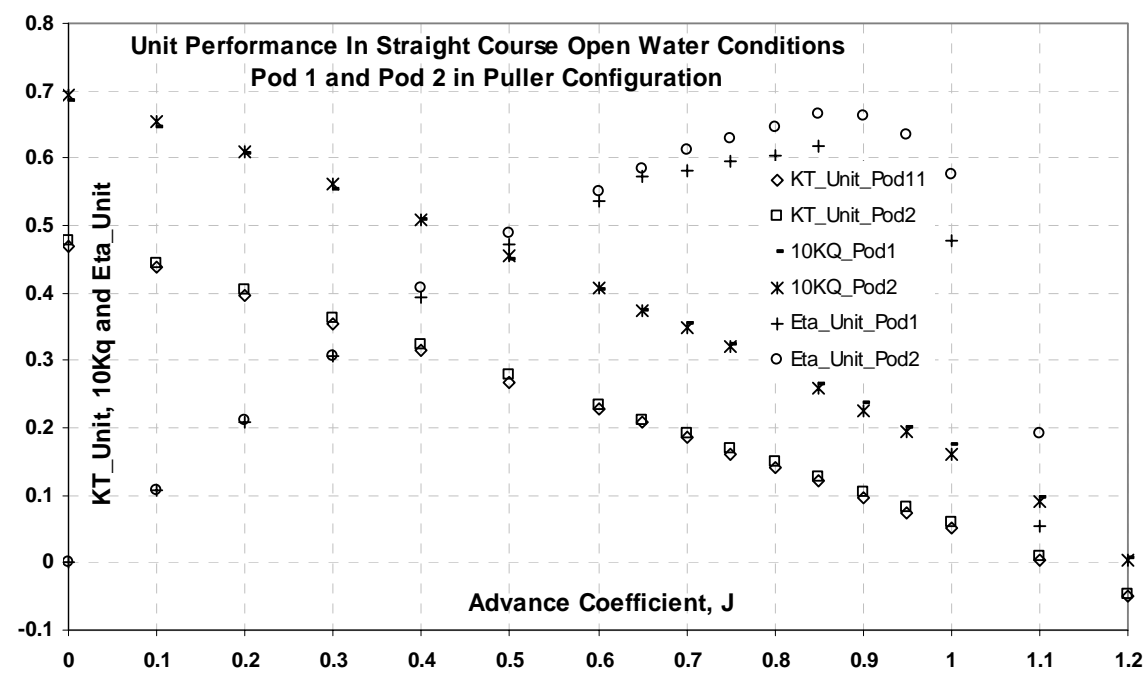

Figure 10: Propulsive performance for the pod units (pod-strut-propeller): Avg. pod 1 and Avg. pod 2.

\subsubsection{Study of Hub angle and Configurations in Straight-Ahead Condition}

Taylor (2005) and Islam et al. (2006b) studied the effect of hub taper angle on the performance of the podded unit in open water conditions. Fig. 10 shows a comparison of unit performance coefficients of two average pods in puller configurations. The conclusions derived from the studies are:

- Puller pod unit outperformed the pusher unit in all advance coefficients in straight ahead 
conditions.

- Increasing the hub taper angle increased the thrust and torque coefficients at low advance coefficient values, both for puller and pusher units.

- $\quad$ Increasing the hub taper angle tended to decrease the maximum efficiency.

- The practical relevance of this finding is that podded propulsion units designed for vessels with low speed, high thrust requirements may be designed with larger taper angles, while podded propulsors designed for more efficient, high speed vessels could be designed with smaller hub angles. In doing so, it may be possible to optimize future podded propeller designs in a manner that broadens the range of application of this rapidly expanding propulsion alternative.

\subsubsection{Study of Pod-Strut-Propeller Geometry}

Karafiath and Lyons (1998) offered the first report that presents a study on the effect of variation in pod geometry on the performance of podded propulsors. Under the current research project, a series of 16 pods were designed using a fractional factorial design technique to study the effects of five geometric parameters (pod diameter, pod length, pod taper length, strut distance and propeller hub angle) of podded propulsors in pusher and puller configurations (Molloy et al. 2005, Islam et al. 2006 and Islam et al. 2007). The definition of the geometric parameters is shown in Fig. 11. Fig. 12 shows one of the pods in the series (pod 4) fitted to the experimental apparatus before being tested. Fig. 13 shows sixteen pod models used with the four propeller models to study the geometric parameters. Each of the 16 pods were tested individually at fixed propeller rotational speed of $11 \mathrm{rps}$ and 17 different advance speeds corresponding to 17 different advance coefficients varied from 0 to 1.2 with 4 or more repeated test runs. The study was done both in puller and pusher configurations because of different inflow conditions. Figs. 14 and 15 show the variation of propeller efficiency with the varied geometry of the pod models in puller and pusher configurations, respectively. The conclusion derived from the study can be summarized as follows:

- $\quad$ Pod diameter, hub angle, and strut distance had significant effects on propulsive performance of both puller and pusher propulsors but with different magnitude and nature.

- Taper length of the pod aft end, the end away from the propeller, did not have a significant influence on performance of the puller propulsors within the range tested. However, it had significant effect on unit thrust of the pusher propulsors at all advance coefficients.

- $\quad$ The interaction of the pod diameter and hub angle had a significant effect on both propeller and unit thrust and torque coefficients at moderate advance coefficient for the puller propulsors.

- For the pusher propulsors, the interaction of the pod length and pod taper length had a noticeable effect on propeller thrust for low advance coefficients.

- $\quad$ For the pusher propulsors, the interaction effect of pod diameter and pod length was significant on unit thrust coefficients at low advance coefficients.

- The measurement showed that there were significant variations in the propeller thrust, torque, unit thrust and propeller and unit efficiencies due to the variations of the geometric parameters of the pods.

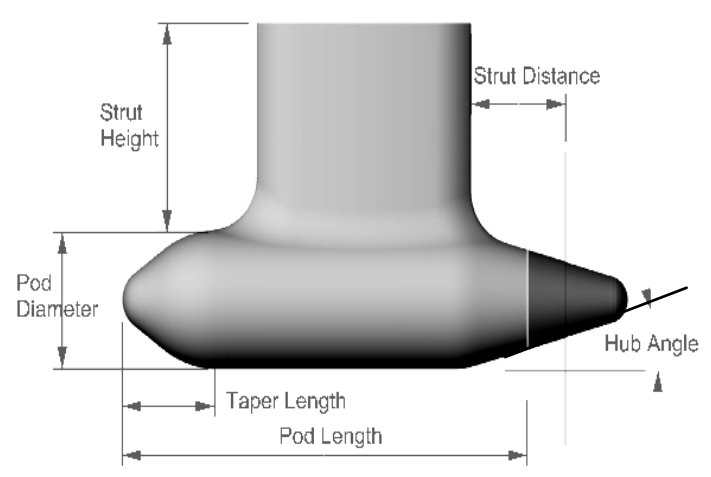

Figure 11: Definition of the geometric parameters.

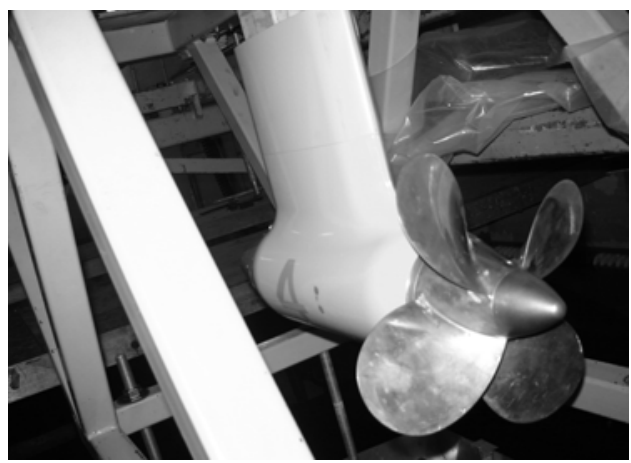

Figure 12: Pod 4 attached to the apparatus before being tested. 


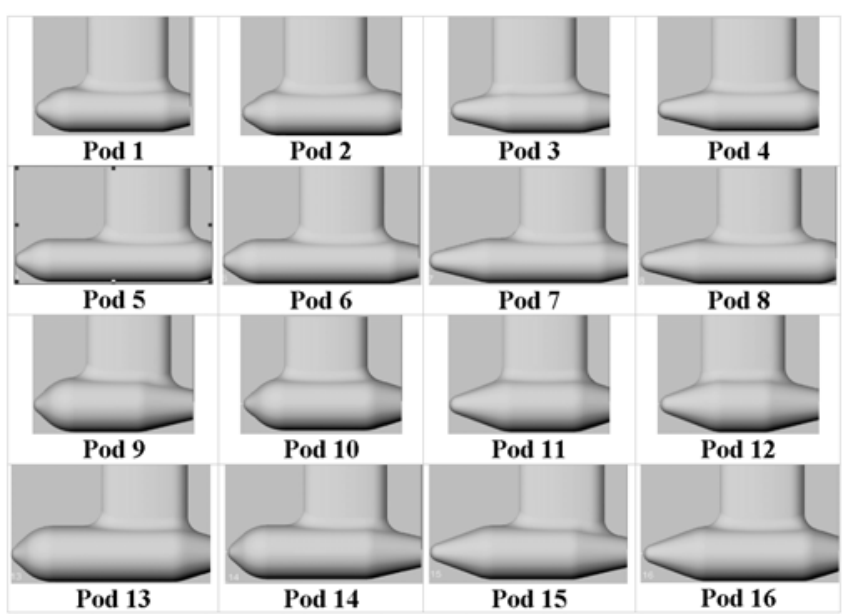

Figure 13: Sixteen pod models.

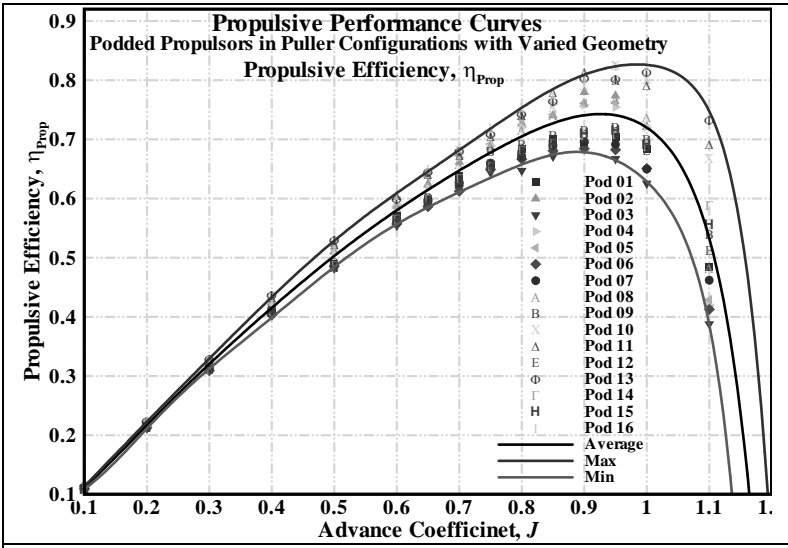

Figure 14: Propulsive efficiency of the propeller of the sixteen model pods in puller configurations.

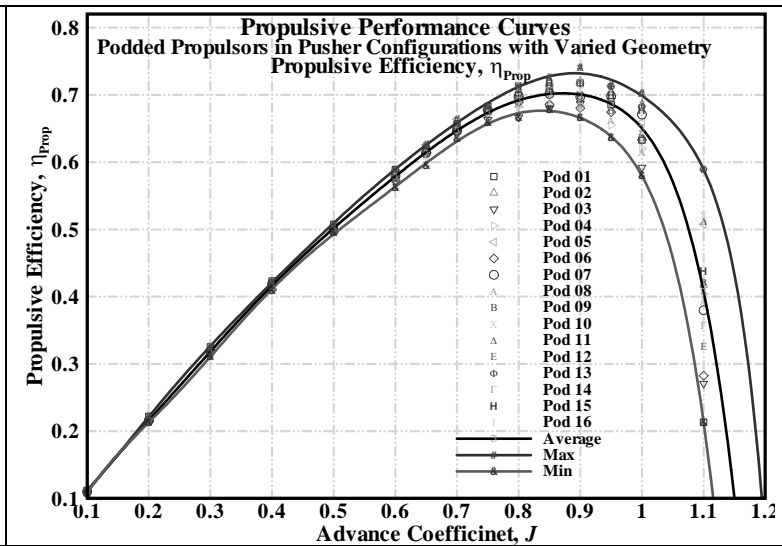

Figure 15: Propulsive efficiency of the propeller of the sixteen model pods in pusher configurations.

\subsubsection{Study at Static Azimuthing conditions}

A few studies have been performed to investigate the performance variations of puller podded propulsor with different static and dynamic azimuthing angles e.g. Szantyr (2001a and 2001b), Grygorowicz and Szantyr (2004), Heinke (2004), Stettler et al. (2004). Under the current project, Islam et al. (2006b and 2007b) investigated the effects of azimuthing conditions on the propulsive performance of podded propulsors in puller and pusher configurations. A model pod fitted with two propellers (for the two configurations) was tested using the custom designed pod testing system (MacNeill et al. 2004). The unit was tested to measure the forces on the whole unit in the three coordinate directions as well as thrust and torque of the propeller for a range of advance coefficients combined with the range of static azimuthing angles from $+30^{\circ}$ to $-30^{\circ}$ with $5^{\circ}$ and $10^{\circ}$ increments. The variations in propulsive performance of the unit with change of azimuthing angle and advance speed in the two configurations were examined. Fig. 16 shows the unit thrust coefficient of the pod in eleven different azimuthing conditions in puller configurations. Fig. 17 shows the unit side force coefficient of the pod unit in pusher configurations in similar azimuthing conditions. 


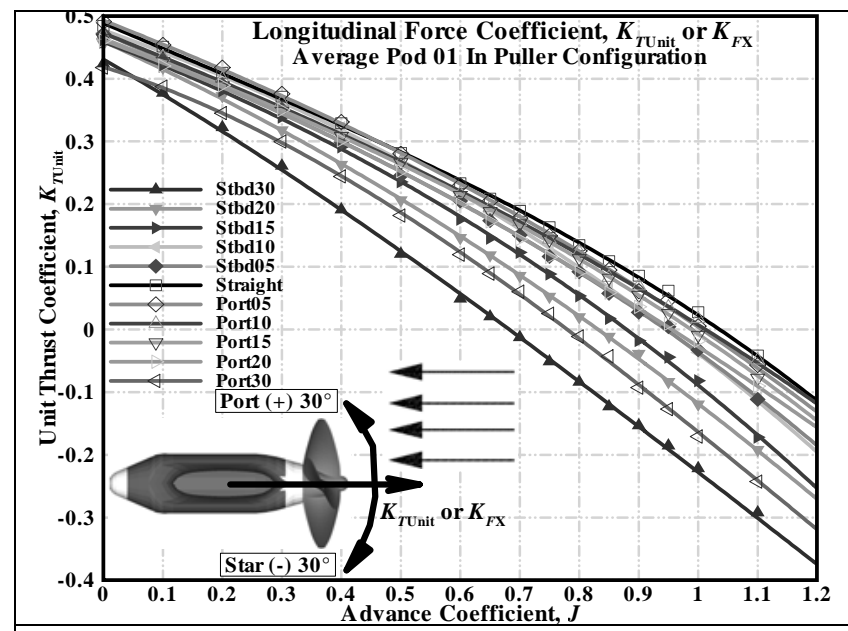

Figure 16: Unit thrust coefficient plots for Pod 1 at different azimuth conditions.

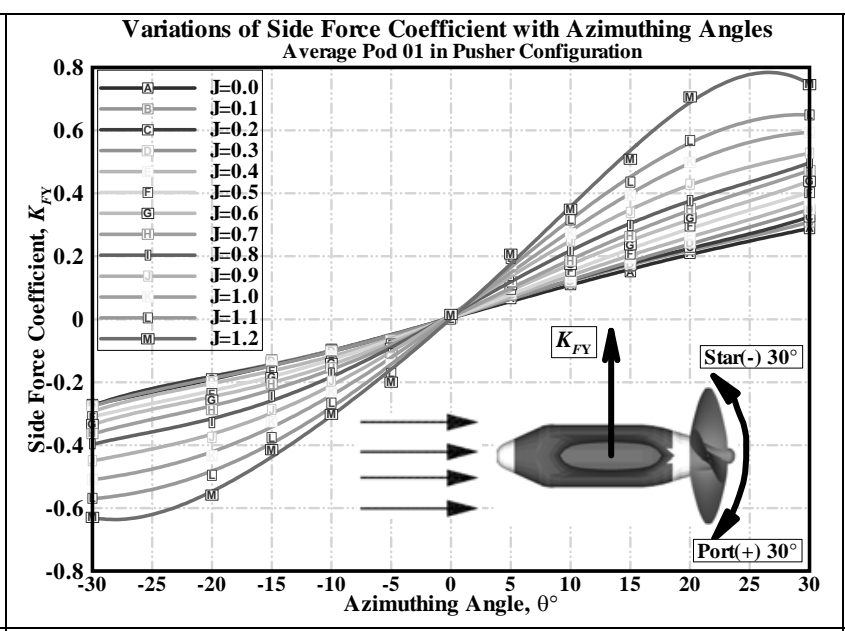

Figure 17: Unit side force coefficient plots for Pod 1 at different azimuth conditions.

The following conclusions were reached from the study.

- In puller configurations, the propeller thrust and torque along the propeller axis remained approximately the same for the two opposite azimuthing angular positions at all advance coefficients. In pusher configuration, for all the advance coefficients, the propeller thrust and torque coefficients were higher than those of the straight course conditions for positive (port) azimuth angles and were lower for negative (starboard) azimuth angles. It was also observed that the propeller thrust and torque were less sensitive to the azimuthing angle in the starboard side than in the port side. Overall, in the puller configurations, the propeller thrust at any advance coefficients and at any azimuthing conditions are higher than those in the corresponding operating conditions in the pusher configurations.

- The unit force and moment coefficients of the propulsors showed a strong dependence on the propeller advance coefficient, azimuth angle and directions.

- In puller configurations, the maximum unit efficiency was found at $5^{\circ}$ portside azimuthing conditions, whereas in pusher configuration, the maximum unit efficiency was found in straight course operating conditions.

- $\quad$ Both in puller and pusher configurations, the propulsor with positive azimuth angles showed an increasing transverse force with the increase of $J$ and the propulsor with negative azimuth angles showed a decreasing transverse force with the increase of $J$. The nature of the curves for the two configurations were different.

- $\quad$ The axial and transverse moment coefficients were also different for the two configurations.

- $\quad$ For pusher configurations, the nature of the steering moment coefficient curves was completely different from those in the puller configurations.

\subsubsection{Study of Pod Gap Distance}

Islam et al. (2007a) presented preliminary results of an experimental study on the effect of gap distance on propulsive characteristics of puller podded propulsors in straight course and static azimuthing open water conditions. The gap distance is the axial distance between the rotating (propeller) and stationary (pod) part of a podded propulsor (see Fig. 18). The experiments consisted of testing of a model pod unit in puller configuration at gap distances of $0.3 \%, 1.0 \%$ and $2.0 \%$ of propeller diameter, at straightahead and $10^{\circ}$ Port, $20^{\circ}$ Port, $-10^{\circ}$ Starboard and $-20^{\circ}$ Starboard azimuthing conditions for the advance coefficient values of 0.0 (bollard pull condition) to 1.2. Tests were also done in pusher configuration at the similar conditions but the data is still being analyzed. Fig. 19 shows the propulsive performance of the pod unit at three different pod gap distances in puller configurations. 


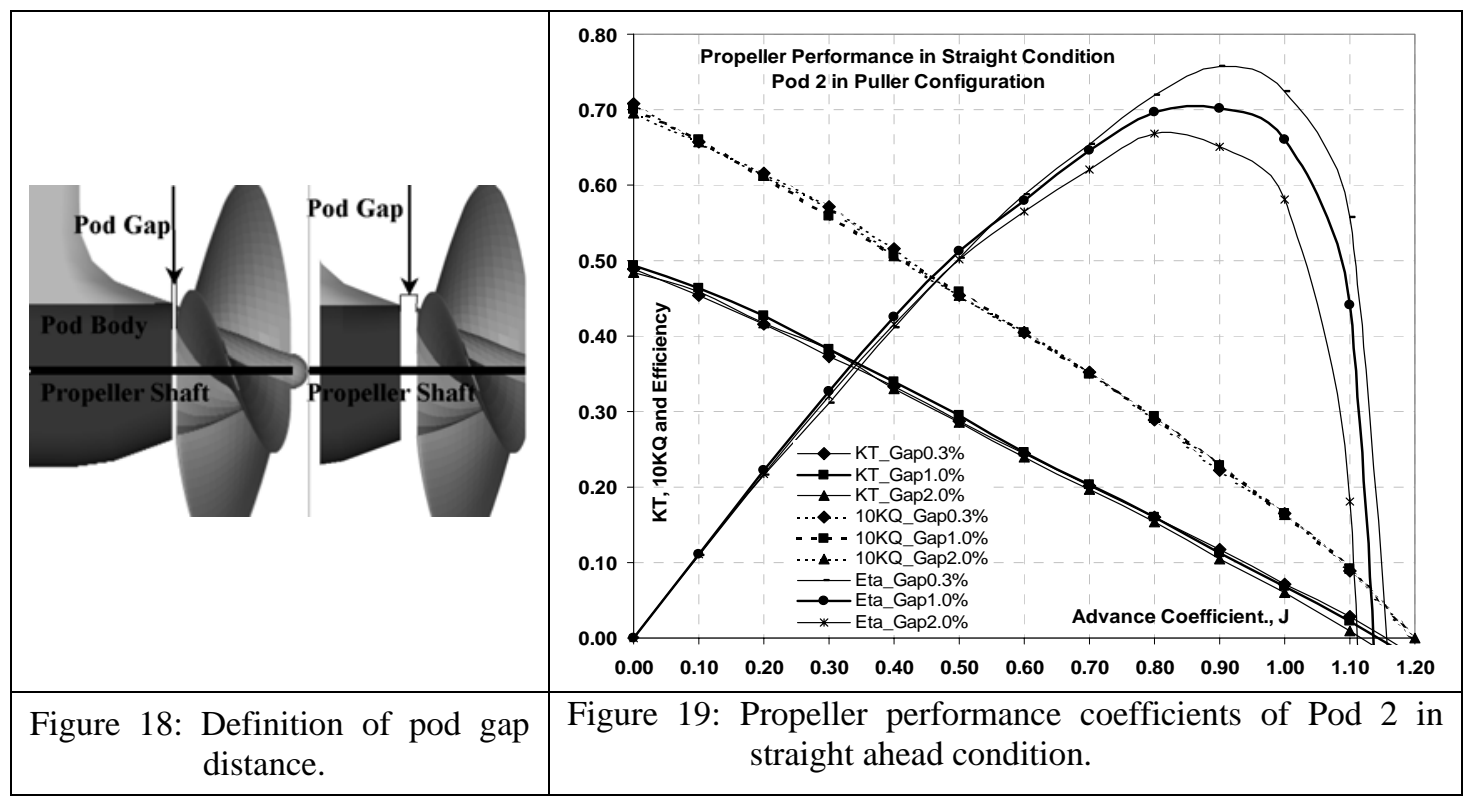

The following conclusions were reached from the study:

- Gap distance did not affect the propeller torque for any of the advance coefficient values in straight-ahead condition. However, the thrust and hence the propulsive efficiency were affected by the change in pod gap distance and the effect was increased with the increase of advance coefficients.

- At azimuthing conditions, both the propeller thrust and torque coefficients were affected by gap distance. The changes in torque coefficients with the change of gap distance were similar for all of the advance coefficient values. However, for propeller thrust coefficient and efficiency, the changes were more obvious at higher advance coefficients.

- The unit thrust and efficiency were not affected by the change in gap distance for any values of advance coefficients in any of the azimuthing conditions. It was also concluded that unit side and vertical force coefficients and unit axial and steering moments were not affected by the change in gap distance both in straight-ahead and azimuthing conditions for any of the advance coefficient values.

\subsubsection{Study of Wake Impingement Effects}

He et al. (2005a) performed an experimental study in a cavitation tunnel on the wake/strut interaction of a podded propeller model. The study included surface pressure measurements on the strut around the leading edge, and visual investigations of cavitation tip vortices. The region of pressure measurements on the strut ranged from 0.6 to 1.2 of the propeller radius, $R$, and from the leading edge downstream to 0.4 of the chord length on both sides of the strut. Within this region, the pressure measurements at 56 different locations were realized by eight repeated tests with seven pressure transducers. The transducers were relocated before each repeated test. Each test consisted of five flow speeds, which varied the advance coefficient.

Fig. 20 shows the test set up in a cavitation tunnel. A cycle of the tip vortex/strut interaction is demonstrated by a set of pictures in Fig. 20. The time averaged pressure coefficient at advance coefficient of 0.81 on the strut surface is given in Fig. 21.

The conclusion derived from the study can be summarized as follows:

- The lowest pressure was found to occur on the stretched side near the leading edge near the intersection of the pod and the strut.

- The largest amplitude of pressure variation was found on the leading edge of the strut around = $1.0 R$, for all tested advance coefficients. 
- In cases of low advance coefficients, the pressure at some measurement points on the compressed side demonstrated a double-trough shape within a single period of the vortex filament impacting process.

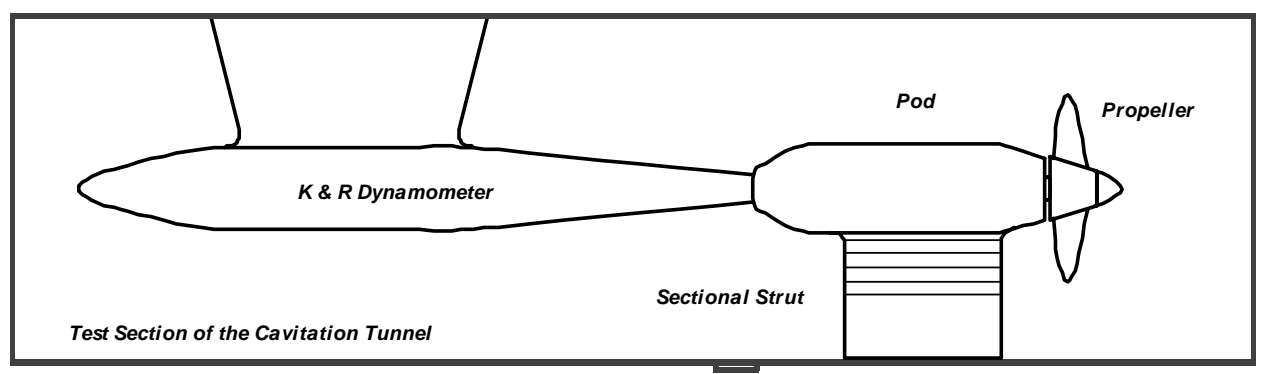

Figure 20: Set-up for the model test of the wake impingement study.

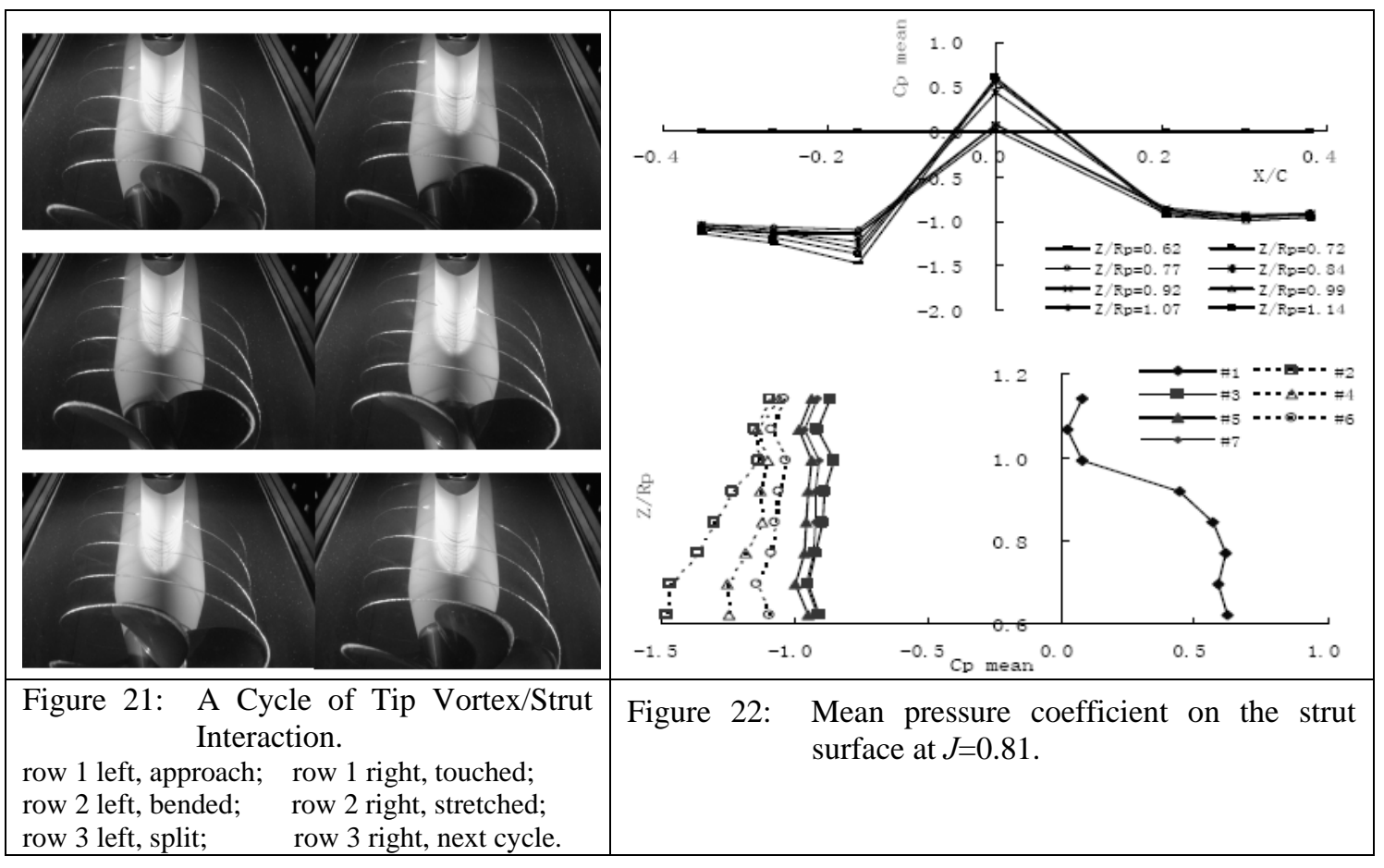

\section{Uncertainty Analysis}

A brief discussion of the levels of uncertainty in the measurements obtained from the instrumentation is given below. To assess the uncertainty in each set of experiments and to identify the major factors influencing these results, a thorough uncertainty analysis was conducted (Islam, 2006). The techniques used were based on adaptations of uncertainty analysis techniques outlined in Hess et al. (2000), ITTC Recommended Procedure (2002), Bose and Luznik (1996) and Coleman and Steele (1999).

The overall uncertainty in the non-dimensional performance coefficients of the podded propulsors required proper identification of all the variables contained within the data reduction expressions (Islam 2006). The experimental approaches used to obtain the data for each of the variables in the expressions were influenced by a variety of elemental sources of error. These elemental sources were estimated, and combined using the root-sum-square (RSS) method to give the bias and precision limits for each of the variables. The bias errors consisted of many elemental sources of error, which depended on the approaches followed to measure the variables. However, for the precision error estimates of most 
variables, only one source of error (repeatability) was considered significant. In order to calculate the uncertainty due to calibration of the six-component dynamometer measurement, it was required to determine how the uncertainties in the calibration data propagate into each element of the interaction matrix and into the measured forces and moments (Islam 2006).

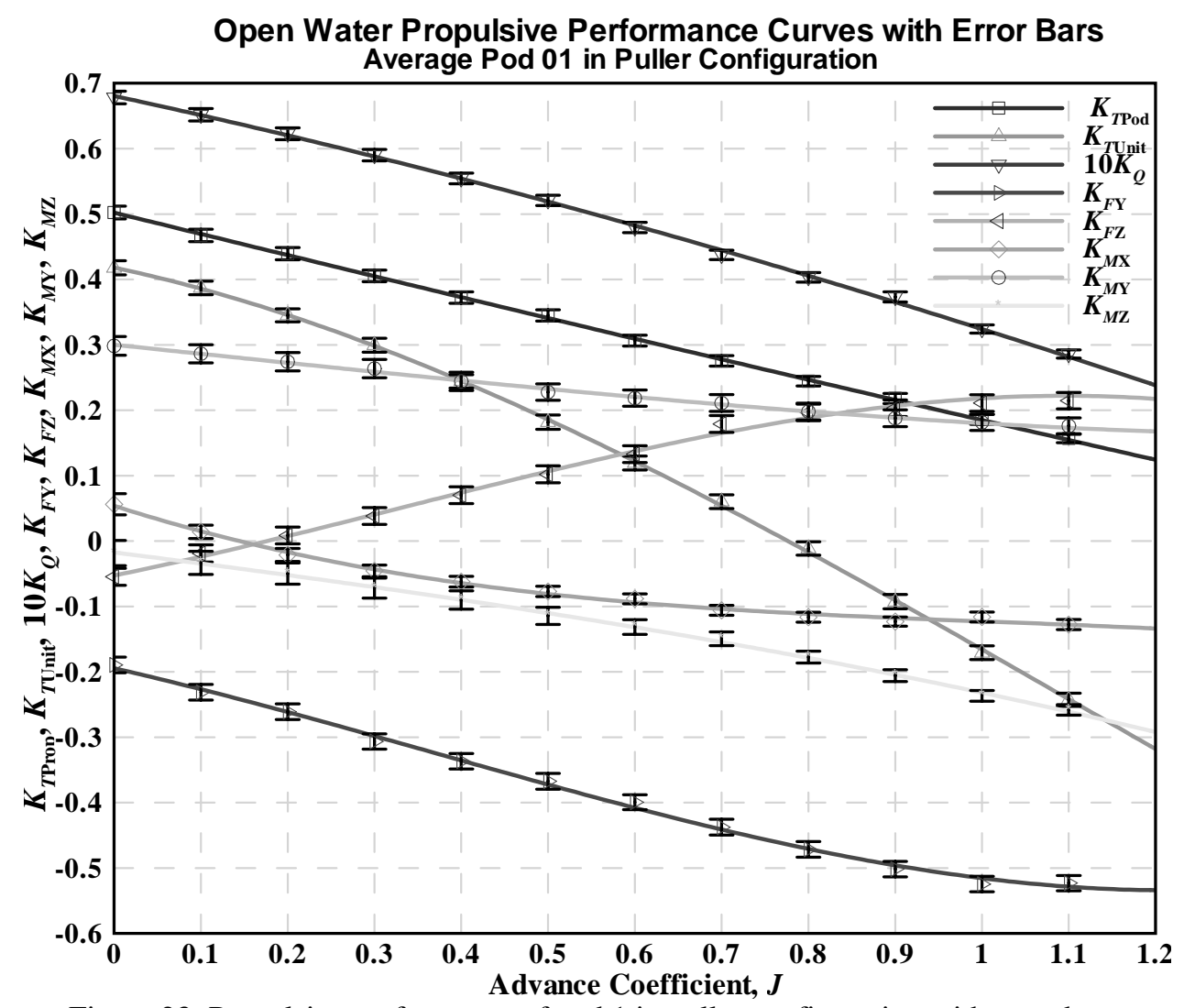

Figure 23: Propulsive performance of pod 1 in puller configuration with error bars.

The error estimates used in the determination of the bias and precision errors in this study were considered to be 95\% coverage estimates. The bias uncertainty and the precision uncertainty were combined using the root-sum-square (RSS) method to provide estimates of overall uncertainty levels in these variables. The overall uncertainty was thus considered to be a $95 \%$ coverage estimate.

The final step in the methodology of uncertainty analysis was to determine how uncertainties in each of the variables propagate through the data reduction equations. Using the approaches described in Bose and Luznik (1996) and Coleman and Steele (1999), the uncertainty expressions for each set of experiments were developed.

Applying the uncertainty limits to the performance curves of the average pod 1 in the puller configuration and at $30^{\circ}$ azimuthing condition, in the form of error bars yields a plot as shown in Fig. 23. From the figure, it is observed that the curves fitted to the data lie inside the error bars. Therefore, the fitted curves provide a good representation of the trends indicated by the results.

\section{Concluding Remarks}

The paper presents a technical overview of the podded propeller projects entitled "Systematic Investigation of Azimuthing Podded Propeller Performance”. The program combined parallel developments in numerical prediction methods and experimental evaluation. The current paper presents a brief overview of the experimental investigations pursued under that project. 
The work addressed gaps in the knowledge concerning podded propeller performance, performance prediction, and performance evaluation. Amongst the hydrodynamic issues that have been addressed are questions regarding the effects of hub taper angle, pod-strut configuration, wake-strut interactions, gap pressure, pod geometry, pod gap effect and static azimuthing conditions on podded propulsor performance.

All of the measurements and the subsequent analyses and interpretations showed consistency. The uncertainty analysis of the measurements showed that the level of uncertainty was within acceptable limits.

\section{Acknowledgement}

The authors thank the Natural Sciences and Engineering Research Council (NSERC) Canada, the National Research Council (NRC), Oceanic Consulting Corp., Thordon Bearings Inc., and Memorial University for their financial and other support. The roles of our research colleagues are also acknowledged with gratitude. In particularly, we recognize the contributions made by Neil Bose, Ayhan Akinturk, Andrew MacNeill, Moqin He, Sue Molloy and Rocky Taylor. Thanks are also extended to Jim Gosse and other technical service staff of Memorial University.

\section{References}

Bose N., and Luznik, L. (1996): Uncertainty Analysis in Propeller Open Water Tests, International Shipbuilding Progress, Vol. 43, no. 435, pp. 237-246.

Coleman, H W., and Steele, W. G.. (1999): Experimentation and Uncertainty Analysis for Engineers, Wiley Interscience.

Galway, R. D. (1980): A Comparison of Methods for Calibration and Use of Multi-Component Strain Gauge Wind Tunnel Balances, Aeronautical Report LR-600, NRC No. 18227, National Aeronautical Establishment, National Research Council, Canada, 40p.

Grygorowicz, M., and Szantyr, J. A. (2004): Open Water Experiments with Two Pods Propulsor Models, In Proc. of the 1st International Conference on Technological Advances in Podded Propulsion, Newcastle University, UK, April, pp. 357-370.

He, M., Veitch, B., Bose, N., and Liu, P. (2005b): An Investigation on Wake/Strut Interaction of a Tractor-Type Podded Propulsor, Proceedings of the $7^{\text {th }}$ CMHSC, Halifax, NS Canada, September 2122, 8p.

He, M., Veitch, B., Bose, N., Bruce, C., and Liu, P. (2005a): Numerical Simulations of Propeller Wake Impacting on a Strut, Proceedings of the CFD2005, St John's, NL Canada, August, 8p.

Heinke, H.J. (2004): Investigation about the Forces and Moments at Podded Drives, In Proc. of the 1st International Conference on Technological Advances in Podded Propulsion, Newcastle University, UK, April, pp. 305-320.

Hess, D.E., Nigon, R.T., and Bedel, J.W. (2000): Dynamometer Calibration and Usage, Research and Development Report No. NSWCCD-50-TR-2000/040, Hydromechanics Directorate, Carderrock Division, Naval Surface Warfare Center, West Bethesda, Maryland, 31p.

Islam M. F., MacNeill A., Veitch B., Akinturk A., and Liu P. (2007a); Gap Effect on Performance of Podded Propulsors in Straight and Static Azimuthing Conditions, CMHSC 2007, St. John's, Canada, 9p.

Islam M. F., Veitch B., Akinturk A., Bose N., and Liu P. (2007b): Experiments with Podded Propulsors in Static Azimuthing Conditions, CMHSC 2007, St. John’s, Canada, 11p.

Islam M. F. (2004): Numerical Investigation on Effects of Hub Taper Angle and Pod-Strut Geometry on Propulsive Performance of Pusher Propeller Configurations, Master of Engineering thesis, Memorial University of Newfoundland, Canada, 136p.

Islam M. F., Molloy S., He M., Veitch B., Bose N., and Liu P. (2006): Hydrodynamic Study of Podded Propulsors with Systematically Varied Geometry, Proceedings, TPOD 2006, Brest, France, 14p. 
Islam M. F., Veitch B., Molloy S., Bose N., and Liu P. (2007): Effects of Geometry Variations on the Performance of Podded Propulsors, To be appeared in SNAME Trans, Florida, USA, 17p.

Islam, M. F. (2006): Uncertainty Analysis of NSERC-NRC Pod Dynamometer System, Ocean Engineering Research Center (OERC) Report No. OERC-2006-05, St. John’s, NL, Canada, 96p.

Islam, M. F., He, M., Veitch, B., and Liu, P. (2007): Cavitation Characteristics of Some Pushing and Pulling Podded Propellers, to be published in the RINA Trans (International Journal of Maritime Engineering, IJME), 9p.

Islam, M. F., Taylor, R., Quinton, J., Veitch, B., Bose, N., Colbourne, B., and Liu, P. (2004): Numerical Investigation of Propulsive Characteristics of Podded Propeller, Proceedings of the 1st International Conference on Technological Advances in Podded Propulsion, Newcastle University, UK, April, pp. 513-525.

Islam, M. F., Veitch, B., Bose, N., and Liu, P. (2006b): Hydrodynamic Characteristics of Pod Propeller Units of Highly Tapered Hub, Proceedings, Propellers/Shafting, Society of Naval Architects and Marine Engineers, Virginia Beach, USA, 12p.

Islam, M. Veitch, B., Bose, N., and Liu, P. (2005): Cavitation Characteristics of Pushing and Pulling Podded Propellers With Different Hub Taper Angles, Proceedings. of the $7^{\text {th }}$ CMHSC, Halifax, NS Canada, September 21-22, 7p.

Islam, M. Veitch, B., Bose, N., and Liu, P. (2006): Numerical Study of Hub Taper Angle on Podded Propeller Performance, Journal of Marine Technology, Vo. 43, No.1, pp.1-10.

ITTC Quality Manual - Recommended Procedures, (2002a): Propulsion, Propulsor Uncertainty Analysis, Example for Open Water Test, 7.5-02-03-02.2, Revision 00.

ITTC Quality Manual - Recommended Procedures, (2002b): Sample Work Instruction: Calibration of Load Cells, 7.6-02-09, Revision 00.

Karafiath, G., and Lyons, D. (1998): Hydrodynamic Performance with Pod Propulsion - U.S. Navy Experience, American Towing Tank Conference, Iowa City, 18p.

Liu, P. (2006): The Design of a Podded Propeller Base Model Geometry and Prediction of its Hydrodynamics, Technical Report no. TR-2006-16, Institute for Ocean Technology, National Research Council, Canada, 16p.

MacNeill, A., Taylor, R., Molloy, S., Bose, N., Veitch, B., Randell, T., and Liu, P. (2004): Design of Model Pod Test Unit, Proceedings of the 1st International Conference on Technological Advances in Podded Propulsion, Newcastle University, UK, April, pp. 447-458.

Molloy, S., Islam, M. F., He, M., Veitch, B., Bose, N., Wang, J., Akinturk, A., and Liu, P. (2005):Use of Factorial Design in Podded Propulsors Geometric Series, Proceedings of the $7^{\text {th }}$ CMHSC, Halifax, NS Canada, September 21-22, 8p.

Montgomery, D.C. (2005): Design and Analysis of Experiments, sixth Edition, Wiley \& Sons, USA, 189p.

Stettler, J. W., Hover, F. S., and Triantafyllou, M. S. (2004): Preliminary Results of Testing on the Dynamics of an Azimuthing Podded Propulsor Relating to Vehicle Maneuvering, In Proc. of the 1st International Conference on Technological Advances in Podded Propulsion, University of Newcastle, UK, pp. 321-338.

Szantyr, J.A. (2001a): Hydrodynamic Model Experiments with Pod Propulsor, International Symposium of Ship Propulsion (Lavrentiev Lectures), State Marine Technical University, St. Petersburg, Russia, pp. 95-104.

Szantyr, J.A. (2001b): Hydrodynamic Model Experiments with Pod Propulsor, Oceanic Engineering International, Vol. 5, No.2, pp. 95-103.

Taylor, R. (2005): Experimental Investigation of the Influence of Hub Taper Angle on the Performance of Push and Pull Configuration Podded Propellers, Master's of Engineering Thesis, Memorial University of Newfoundland, Canada, 120p.

Taylor, R., Veitch, B., and Bose, N. (2005): The Influence of Hub Taper Angle on Podded Propeller Performance: 'Propeller Only' Tests vs. 'Podded Propeller Unit' Tests, Proceedings of the $7^{\text {th }}$ CMHSC, Halifax, NS Canada, September 21-22, 8p. 